\title{
Carbon molecular sieves as model active electrode materials in supercapacitors
}

V. Ruiz ${ }^{1}$, C. Blanco ${ }^{1}$, R. Santamaría ${ }^{1}$, J.M. Juárez-Galán ${ }^{2}$, A. Sepúlveda-Escribano ${ }^{2}$, F. RodríguezReinoso $^{2}$

${ }^{1}$ Instituto Nacional del Carbón (CSIC), Apdo. 73, 33080 Oviedo, Spain

${ }^{2}$ Dept. Química Inorgánica, Universidad de Alicante, Apdo. 99, 03080 Alicante, Spain

Abstract.- Various microporous carbon molecular sieves are studied as active electrode material for supercapacitors in order to clarify the controversy about the accessibility of the electrolyte to the micropores. Cyclic voltammetry experiments were performed in electrolytes with different ion size. The results showed a clear ion sieving effect when the porosity of the carbon was similar to that of the ions of the electrolyte. Impedance spectroscopy was also useful to evidence diffusion restrictions of the ions into the pores. The results obtained in this study clearly demonstrate that in aqueous media very narrow micropores $(0.5 \mathrm{~nm})$ are still capable of forming the electrical double layer. Therefore, the majority of microporous carbons, with wider porosity, are perfectly suitable as active electrode materials for supercapacitors when aqueous electrolytes are used.

\section{Keywords}

(Activated carbon, molecular sieves, electrochemical properties)

\footnotetext{
* Corresponding author: clara@incar.csic.es; Tel.: + 349851190 90; Fax.: + 34985297662
} 


\section{1.- INTRODUCTION}

The performance of activated carbon as electrode in supercapacitors has been mainly related to its surface area and pore size. However, the role of pore size on the formation of the electric double layer is still under discussion as a consequence of the heterogeneous porous texture of activated carbons [1]. The development of mesoporous carbons obtained using the template technique has facilitated the understanding of the role of mesopores because they have rather homogeneous pore size [2]. In the case of microporous carbons there are no systematic studies to date allowing the determination of the minimum pore size that is accessible to a given electrolyte. The situation is so complex that even the suitability of microporous carbons for this application has been questioned based on the probable restrictions for the diffusion of the electrolyte into the porous network [3]. Nonetheless, there are studies that point out an anomalous increase in carbon capacitance at pores smaller than $1 \mathrm{~nm}$ [4]. Eliad et al. [5] investigated the relationship between the size of different electrolytes and the pore size estimated for activated carbons derived from cellulose. However, it is not easy to raise definite conclusions when standard activated carbons are used due to their wide pore size distribution. Therefore, the use of carbon molecular sieves with relatively homogeneous microporosity should facilitate the study on this topic.

In this study, various microporous carbon molecular sieves were used as active electrode material for supercapacitors. Although high capacitance is not expected from these samples due to their low surface area, the results would contribute to clarify the controversy about the accessibility of the electrolyte to the micropores. 


\section{2.- EXPERIMENTAL}

Two commercial carbon molecular sieves supplied by Mitsubishi Co., the socalled Takeda CMS3A and CMS5A, and one molecular sieve obtained by activation of coconut shells with $\mathrm{CO}_{2}$ at $1073 \mathrm{~K}$ for $4 \mathrm{~h}(\mathrm{CW} 4)$ [6] were used in this study. Physical adsorption of $\mathrm{N}_{2}$ at $77 \mathrm{~K}$ and of $\mathrm{CO}_{2}$ at $273 \mathrm{~K}$ were used for the characterisation of the porous texture of the carbons [7]. The microporosity of the samples was further analysed by measuring the enthalpy of immersion of the carbon molecular sieves into liquids of different molecular dimensions: dichloromethane $(0.33 \mathrm{~nm})$, benzene $(0.37$ $\mathrm{nm})$, cyclohexane $(0.48 \mathrm{~nm}), 2,2$ dimethylbutane $(0.56 \mathrm{~nm})$, and $\alpha$-pinene $(0.70 \mathrm{~nm})$ [8].

The electrochemical performance of the samples was studied on coin-type electrodes prepared by using 15 wt. \% of poly (vinylidene fluoride), PVDF, as binder. Two electrode capacitors were built with a glassy fibrous separator and gold current collectors, using a Teflon Swagelok ${ }^{\circledR}$ system. The values of capacitance were estimated on two-electrode cells from galvanostatic charge/discharge cycling between 0.88 and 88 $\mathrm{mA} / \mathrm{cm}^{2}(18-1800 \mathrm{~mA} / \mathrm{g})$, using $2 \mathrm{M} \mathrm{H}_{2} \mathrm{SO}_{4}$ as electrolyte. Additionally, aqueous electrolytes of different cation size $\left(\mathrm{LiCl}, \mathrm{NaCl}, \mathrm{KCl}, \mathrm{CaCl}_{2}\right)$ were selected as ion probes in order to study the accessibility of the electrolyte into the micropores. Their Stokes radius are: $\mathrm{Rs}\left(\mathrm{Li}^{+}\right)=0.24 \mathrm{~nm} ; \mathrm{Rs}\left(\mathrm{Na}^{+}\right)=0.19 \mathrm{~nm} ; \mathrm{Rs}\left(\mathrm{K}^{+}\right)=0.13 \mathrm{~nm} ; \mathrm{Rs}^{+}\left(\mathrm{Ca}^{2+}\right)=$ $0.31 \mathrm{~nm} ; \mathrm{Rs}\left(\mathrm{Cl}^{-}\right)=0.12 \mathrm{~nm}$. Voltammetry experiments were done in three-electrode cells using $\mathrm{Pt}$ and $\mathrm{Hg} / \mathrm{Hg}_{2} \mathrm{SO}_{4}$ as auxiliary and reference electrodes, respectively, when $\mathrm{H}_{2} \mathrm{SO}_{4}$ was used as electrolyte and $\mathrm{Pt}$ and $\mathrm{Ag} / \mathrm{AgCl}$ as auxiliary and reference electrodes, respectively for the rest of the electrolytes studied. All potentials are reported versus normal hydrogen electrode (NHE). Measurements were performed at 
scan rates at $0.2 \mathrm{mV} / \mathrm{s}$. Impedance spectroscopy measurements were performed at different potentials in order to study the restrictions to the diffusion of the ions in the pores either in the anodic or the cathodic region. Tests were performed using the threeelectrode cell configuration at $-0.2 \mathrm{~V}$ and $+0.6 \mathrm{~V}$ vs NHE, in a frequency range from 1 $\mathrm{mHz}$ to $100 \mathrm{KHz}$. An ac amplitude of $10 \mathrm{mV}$ was applied to reach the voltage required. The results were express in the form of Nyquist plots and in terms of the variation of the resistance (Z') with frequency.

\section{3.- RESULTS AND DISCUSSION}

The textural characteristics of the carbon molecular sieves are summarised in Table 1. Sample CMS3A has very narrow microporosity, which is not accessible to $\mathrm{N}_{2}$ at $77 \mathrm{~K}$. Immersion calorimetry into the liquid of smallest molecular size $\left(\mathrm{CH}_{2} \mathrm{Cl}_{2}, 0.33\right.$ $\mathrm{nm}$ ) is also negligible, which is indicative of the small porosity present in this sample. Values of pore size between 0.3 and $0.4 \mathrm{~nm}$ have been reported in the literature for this sample [9]. On the other hand, the $\mathrm{CO}_{2}$ adsorption at $273 \mathrm{~K}$ provides a volume of narrow micropores of $0.22 \mathrm{~cm}^{3} / \mathrm{g}$. Sample CW4 has wider microporosity than CMS3A, but the differences obtained between the $\mathrm{N}_{2}$ and $\mathrm{CO}_{2}$ isotherms $\left(\mathrm{V}_{\mathrm{N} 2}<\mathrm{V}_{\mathrm{CO} 2}\right)$ indicate the presence of narrow microporosity also in this sample $[6,7]$. The micropores present in sample CMS5A, although still narrow, are slightly wider than those present in CW4, as the difference between the adsorption of $\mathrm{N}_{2}$ and $\mathrm{CO}_{2}$ is not as large [7]. The results obtained by immersion calorimetry (Table 1) indicate that most of the microporosity of sample CW4 is below $0.48 \mathrm{~nm}$, while that present in CMS5A is slightly wider, with a larger contribution between 0.48 and $0.56 \mathrm{~nm}$. This carbon molecular sieve is wellknown and it has been characterized in detail elsewhere [6]. 
Cyclic voltammetry experiments performed on the sample with the narrowest porosity (CMS3A) did not yield any capacitance even in the electrolyte of smallest dimensions $(\mathrm{KCl})$ due to the restricted accessibility. Figure 1-a shows the voltammograms obtained for $\mathrm{CW} 4$ using $\mathrm{LiCl}, \mathrm{NaCl}, \mathrm{KCl}$ and $\mathrm{CaCl}_{2}$ as electrolytes. While the capacitance values obtained for the anion adsorption are similar for all the electrolytes (the anion is common to all of them), some differences can be observed in the region of cation adsorption. The most significant one is the drastic reduction of capacitance obtained when $\mathrm{CaCl}_{2}$ was used as electrolyte, this indicating a clear sieving effect for $\mathrm{Ca}^{2+}$ due to the restricted accessibility of this cation to the carbon porosity. In fact, the Stokes radius for $\mathrm{Ca}^{2+}$ is $0.31 \mathrm{~nm}(0.62 \mathrm{~nm}$ diameter $)$ and the pore diameter for this carbon is essentially smaller than $0.48 \mathrm{~nm}$. The capacitance obtained for the other three electrolytes in the range of anion adsorption is similar, only slightly lower for $\mathrm{NaCl}$ and $\mathrm{LiCl}$ with respect to $\mathrm{KCl}$, but no clear sieving effect is observed.

The results obtained for CW4 by impedance spectroscopy performed at different voltages for the electrolytes are shown in Figure 2 and 3. The Nyquist plots corresponding to $\mathrm{LiCl}$ show no significant differences between the experiments performed at -0.2 and $+0.6 \mathrm{~V}$ vs NHE (Figure 2-a). On the contrary, the results obtained for $\mathrm{CaCl}_{2}$ (Figure 2-b) show a significantly higher diffusive resistivity for the $\mathrm{Ca}^{2+}$ ions, which is in agreement with the results obtained in cyclic voltammetry.

Further information from the impedance experiments performed was obtained by studying the variation of the resistance (real component of impedance) with frequency (Figure 3). The resistance obtained at high frequencies arise from physical 
phenomena without kinetic limitations. On the other hand, in the low frequency range the resistance can be assigned to kinetic controlled processes. In this case, where very narrow microporosity exists, it can be associated to the diffusion of the ions in the porous network. When $\mathrm{LiCl}$ is used as electrolyte, (Figure 3-a), the resistance at low frequencies is similar both at the positive and negative voltages. On the contrary, the resistance obtained for $\mathrm{CaCl}_{2}$ in the cation adsorption region is extremely higher than that obtained in the anodic one (Figure 3-b), indicating severe restrictions for the diffusion of the $\mathrm{Ca}^{2+}$ ions into the pores of sample CW4. This is in agreement with the results obtained by cyclic voltametry (Figure 1-a).

Figure 1-b shows the results obtained for CMS5A using the different electrolytes. The values of specific capacitance obtained for this sample in $\mathrm{NaCl}, \mathrm{KCl}$ and $\mathrm{LiCl}$ are similar, both in the anodic and cathodic region. This indicates that the pores in this sample are accessible to cations with high hydration shell, such as $\mathrm{Li}^{+}$(Rs $=0.24 \mathrm{~nm})$. However, there is a significant reduction in capacitance in the range of cations adsorption when $\mathrm{CaCl}_{2}(\mathrm{Rs}=0.31 \mathrm{~nm})$ is used, although not as pronounced as for sieve CW4. This is in agreement with the size of the microporosity found in this sample (Table 1), which is mainly smaller than $0.48 \mathrm{~nm}$, but a part of it being between 0.48 and $0.56 \mathrm{~nm}$. Impedance spectroscopy tests performed on this sample did not show clear differences in diffusion resistance between the anodic and cathodic region, in contrast to sieve CW4.

Studies were also preformed in sulfuric acid in order to understand the role of pore size in a widely used electrolyte. Figure 4-a shows the capacitance values of the 
different molecular sieves obtained from galvanostatic charge-discharge cycles performed in two-electrode cells. Cycling CMS3A yields negligible capacitance, due to the small pore size of this sample. On the other hand, CMS5A showed values of capacitance which are comparable to many other activated carbons described in the literature [10]. This clearly indicates that micropores, even as narrow as $0.5 \mathrm{~nm}$, are suitable for the formation of the electric double layer in this media. It is also noticeable that sample CW4, with slightly narrower porosity (Table 1), shows a drastic decrease in capacitance. This seems to indicate that the minimum pore size accessible to the $\mathrm{HSO}_{4}{ }^{-}$ ions is around $0.5 \mathrm{~nm}$.

The three-electrode configuration was also used to explain the different performance of CW4 and CMS5A in sulfuric acid (Figure 4-b). The comparison between the voltammograms shows the evident sieving effect in the anodic branch of the $\mathrm{CV}$, indicating that the access of the $\mathrm{HSO}_{4}{ }^{-}$anions $(\mathrm{Rs}=0.184 \mathrm{~nm})$ to the pores in sample CW4 is severely restricted. This behaviour in sulfuric acid supports the results obtained in the two electrode configuration, where very low capacitance values were obtained for CW4 (Figure 4-a). It is worth noting that now the ion sieving effect is observed at a smaller ionic size than in the cathodic region. This could be due to the difference in $\mathrm{pH}$ of sulfuric acid and the other electrolytes studied, as the surface of the carbon is likely to be strongly protonated in the strong acidic media.

\section{4.- CONCLUSIONS}

The use of carbon molecular sieves as model electrode active materials in supercapacitors enables the determination of the minimum pore size which is accessible 
to a given electrolyte. The results obtained in this study clearly demonstrate that very narrow micropores $(0.5 \mathrm{~nm})$ are still capable of forming the electrical double layer in aqueous media. Therefore, the majority of microporous carbons, with wider porosity, should be perfectly suitable as active electrode materials for supercapacitors when aqueous electrolytes are used.

Acknowledgements.- This work has been performed with financial support from MICYT (project MAT2004-03480-C02) and FICYT (project IB05-086-C1). V. Ruiz acknowledges a predoctoral research grant from FICYT.

\section{References}

1.- H. Marsh, F. Rodríguez-Reinoso. Activated Carbon. Elsevier, Oxford (UK), 2006.

2.- C. Vix-Guterl, E. Frackowiak, K. Jurewicz, M. Friebe, J. Parmentier, F. Béguin, Carbon 43 (2005)1293-1302.

3.- F.C. Wu, R.L. Tseng, C.C. Hu, C.C. Wang, J. of Power Sources 144 (2005) 302-309.

4.- J. Chmiola, G. Yushin, Y. Gogotsi, C. Portet, P. Simon, P.L. Taberna, Science 313 (2006) 760-762.

5.- L. Eliad, G. Salitra, A. Soffer, D. Aurbach, J.Phys. Chem. B 105 (2001) 6880-6887.

6.- C.G. De Salazar, A. Sepúlveda-Escribano, F. Rodríguez-Reinoso. Stud. Surf. Sci. Catal. 128 (2000) 303-312.

7.- F. Rodríguez-Reinoso, J. Garrido, J.M. Martín-Martínez, R. Torregrosa, M. MolinaSabio, Carbon 27 (1989) 23-32. 
8.- J. Silvestre-Albero, C. Gómez de Salazar, A. Sepúlveda-Escribano, F. RodríguezReinoso, Coll. Surf. A: Phys. Eng. Asp. 187-188 (2001) 151-165.

9.- S.W. Rutherford, D.D. Do, Langmuir 16 (2000) 7245-7254.

10.- T.A. Centeno, F. Stoeckli, Electrochimica Acta 52 (2006) 560-566. 
TABLE 1. - Textural characteristics of the carbon molecular sieves.

\begin{tabular}{ccccccccc}
\hline \multirow{2}{*}{ Sample } & $\mathrm{V}_{\mathrm{N} 2}$ & $\mathrm{~V}_{\mathrm{CO} 2}$ & \multicolumn{5}{c}{$-\Delta \mathrm{Hi}(\mathrm{J} / \mathrm{g})$} \\
\cline { 6 - 9 } & & $\left(\mathrm{cm}^{3} / \mathrm{g}\right)$ & $\left(\mathrm{cm}^{3} / \mathrm{g}\right)$ & $\mathrm{CH}_{2} \mathrm{Cl}_{2}$ & $\mathrm{C}_{6} \mathrm{H}_{6}$ & $\mathrm{C}_{6} \mathrm{H}_{12}$ & $2.2-\mathrm{DMB}$ & a-pinene \\
\hline CMS3A & - & 0.22 & 3.30 & 0 & - & - & - \\
CMS5A & 0.22 & 0.27 & 92.15 & 82 & 37 & 13 & 0 \\
CW4 & 0.17 & 0.30 & 88.56 & 79 & 16 & 7 & 0 \\
\hline
\end{tabular}

2,2-DMB: 2,2-dimethylbutane 


\section{Figure Captions}

Figure 1.- Cyclic voltammetry (three-electrode configuration) at $0.2 \mathrm{mV} / \mathrm{s}$ of sample: a) CW4 and b) CMS5A, using different electrolytes.

Figure 2.- Nyquist plots for sample CW4 (in three-electrode configuration) at different cell potentials: a) in $\mathrm{LiCl}$ and b) in $\mathrm{CaCl}_{2}$.

Figure 3.- Resistance vs. frequency of sample CW4 (in three-electrode configuration) at different cell potentials: a) in $\mathrm{LiCl}$ and b) in $\mathrm{CaCl}_{2}$.

Figure 4.- Electrochemical behaviour of samples in $2 \mathrm{M} \mathrm{H}_{2} \mathrm{SO}_{4}$ : a) Specific capacitance obtained from galvanostatic cycling in two-electrode cell configuration and b) Cyclic voltammetry in three-electrode cell configuration at $0.2 \mathrm{mV} / \mathrm{s}$. 
a)

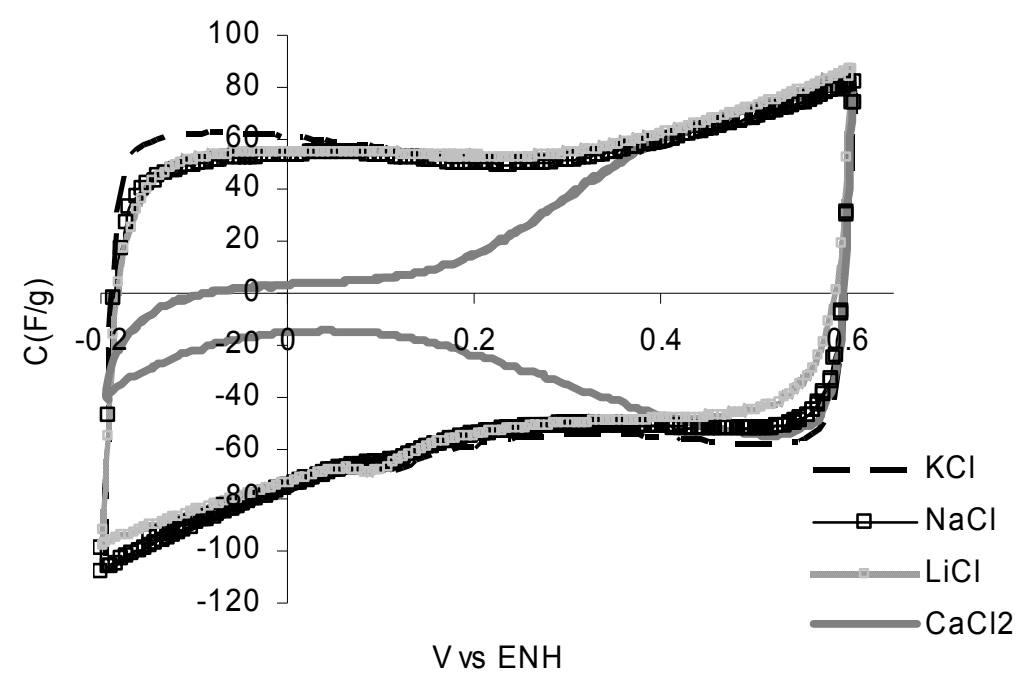

b)

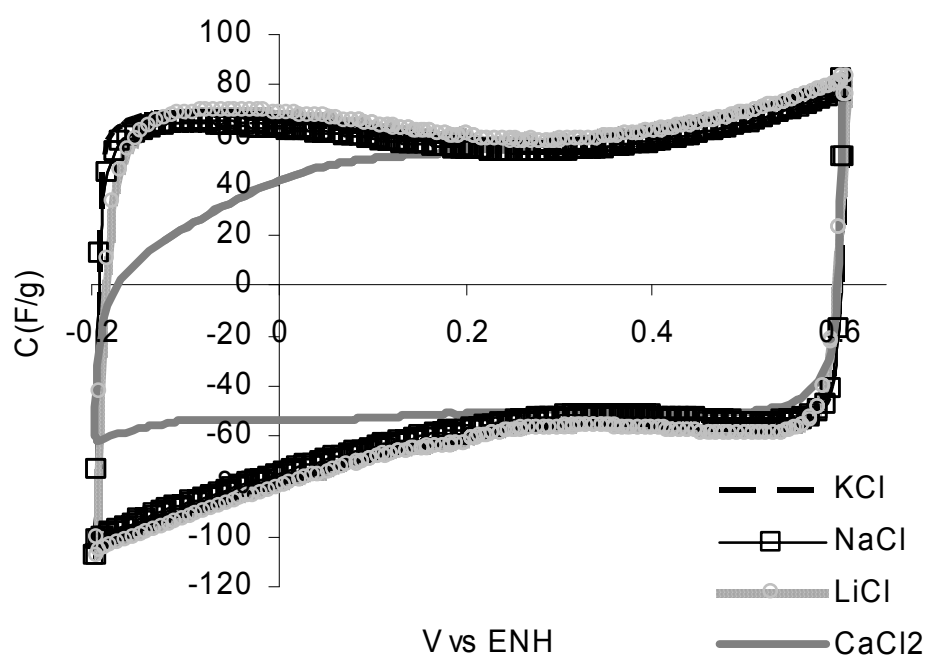

Figure 1 
a)

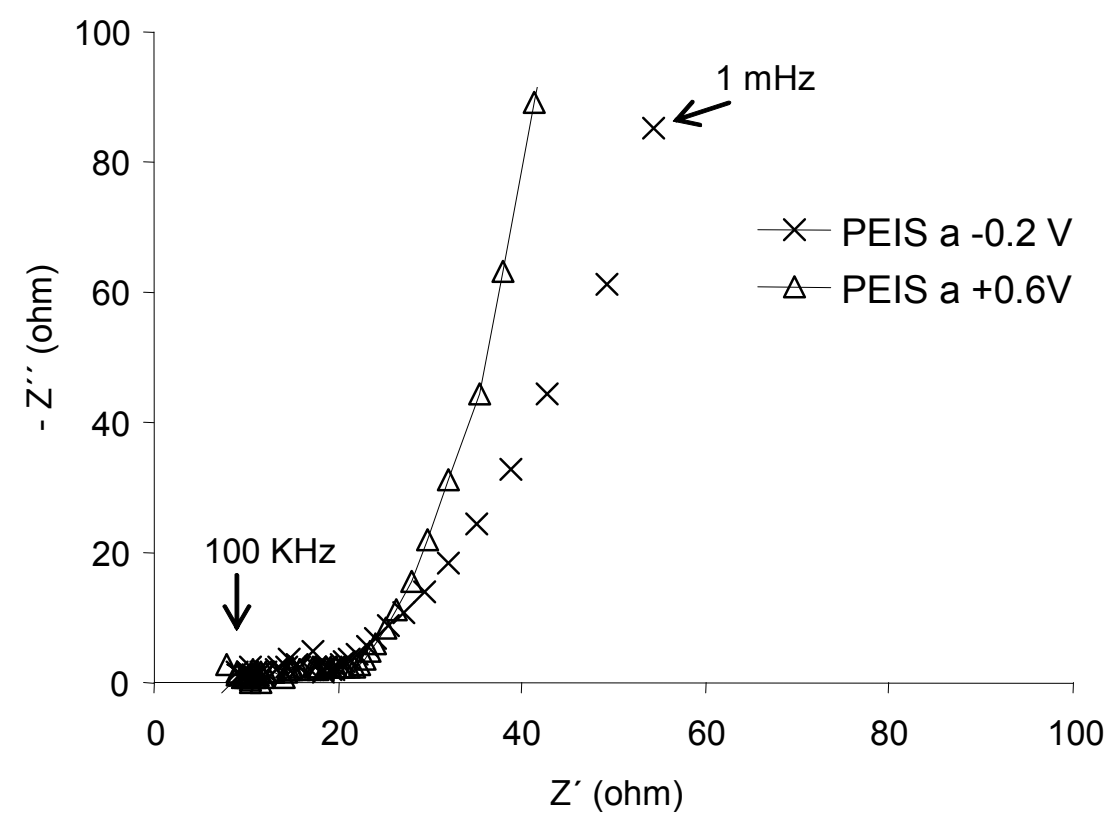

b)

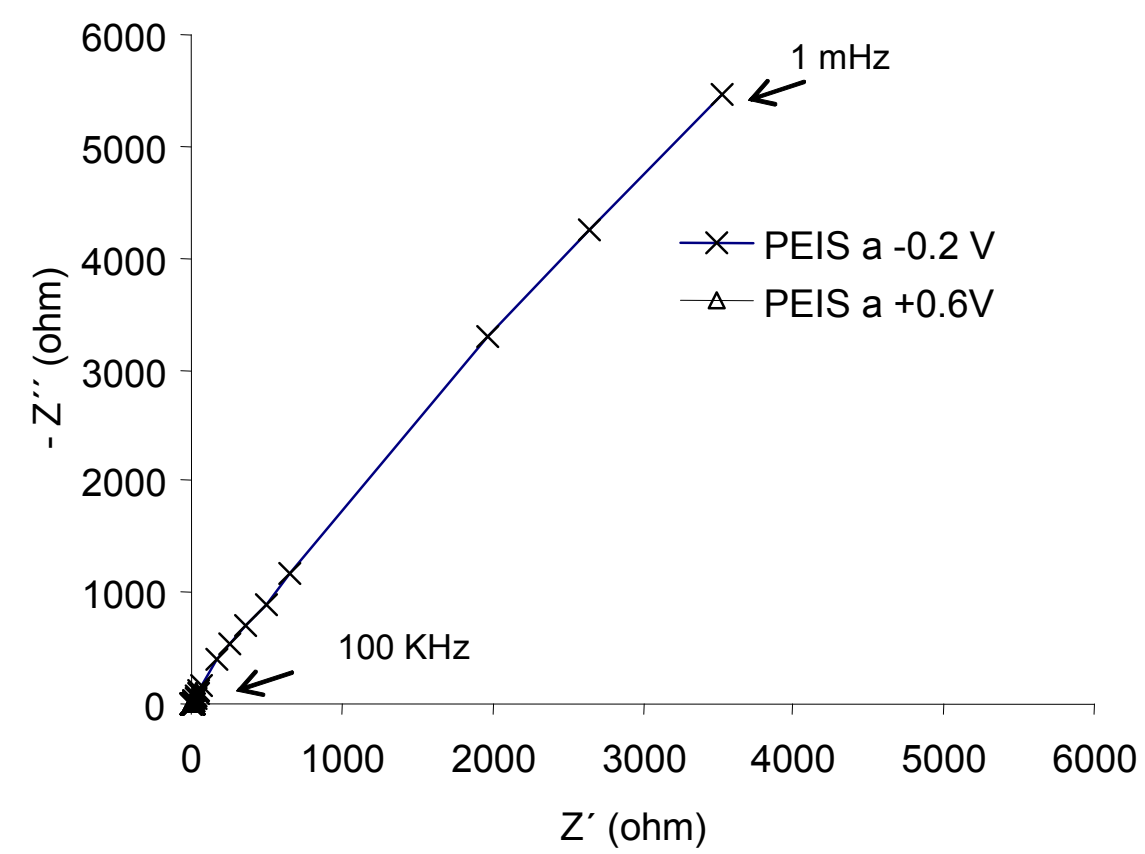

Figure 2 
a)

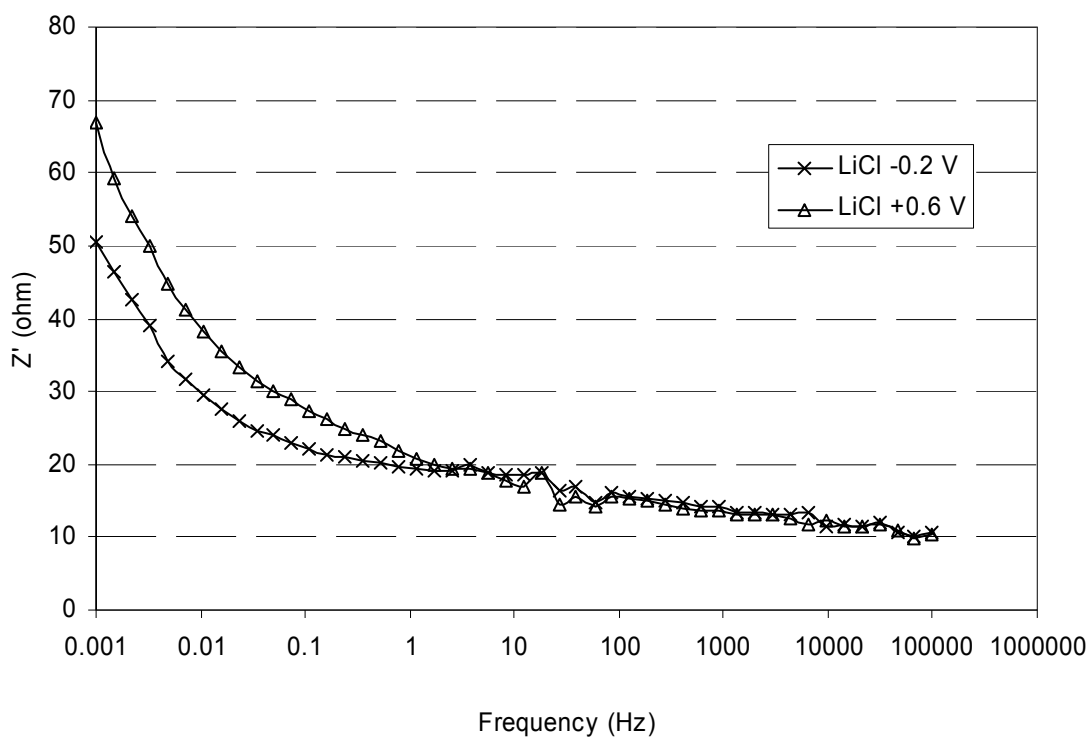

b)

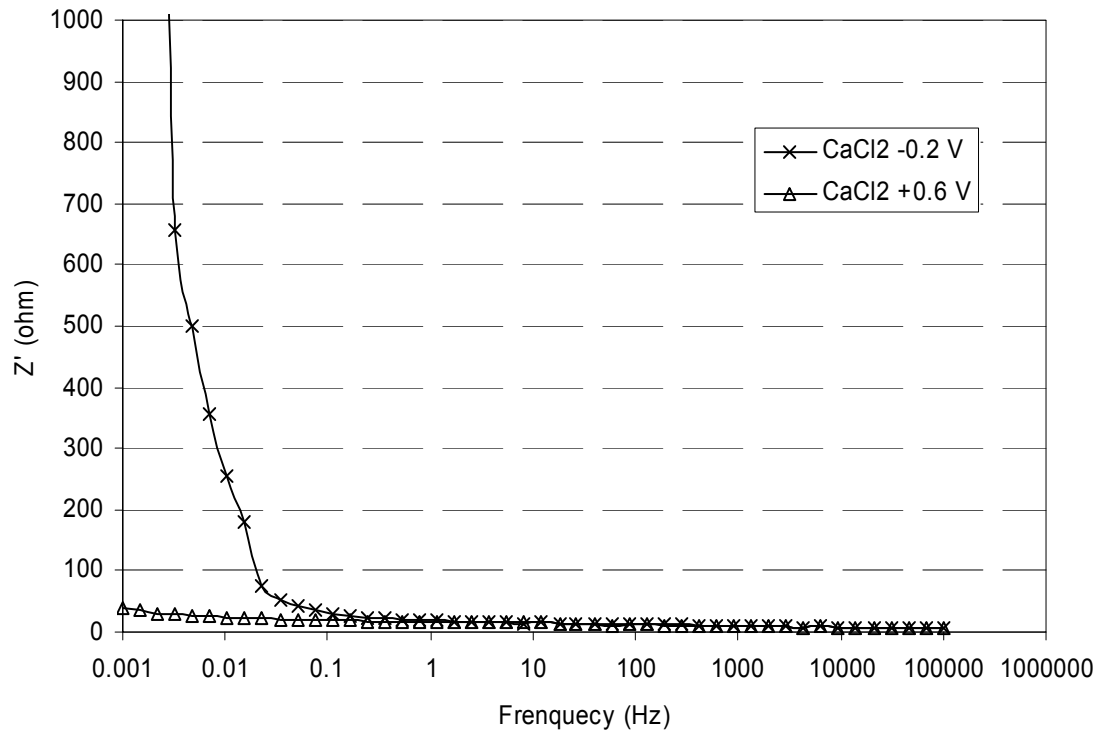

Figure 3 
a)

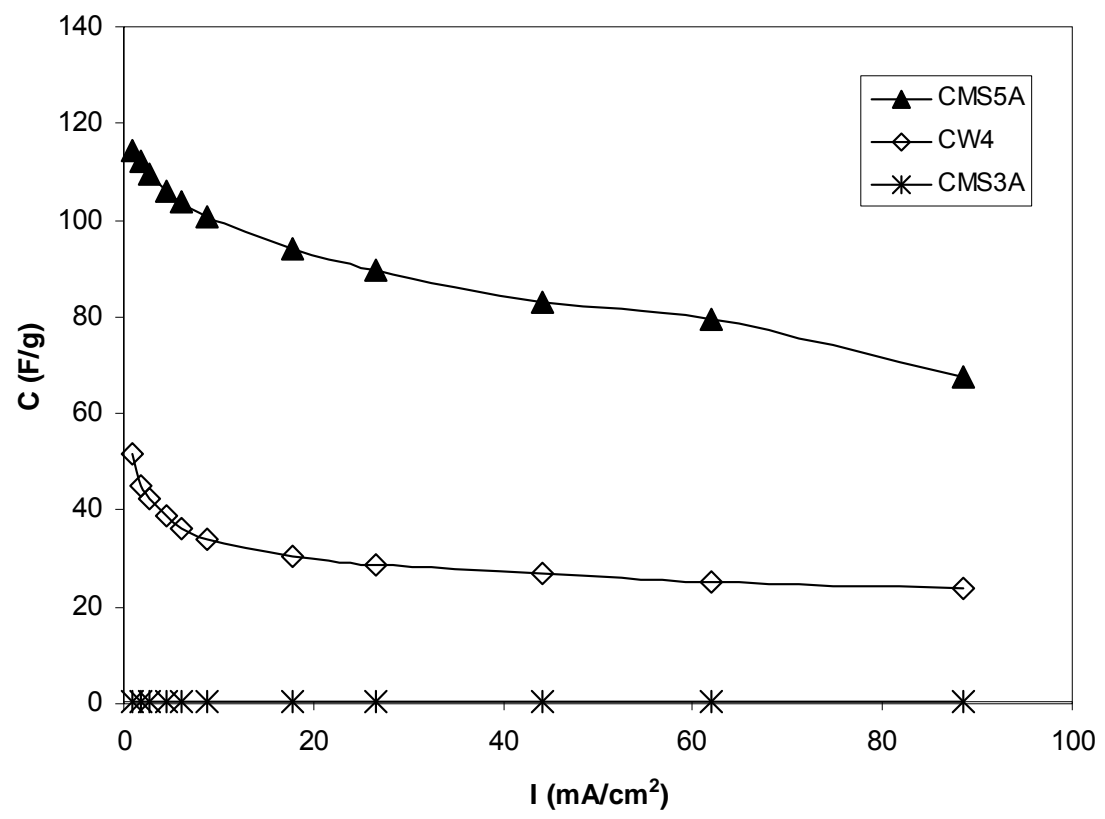

b)

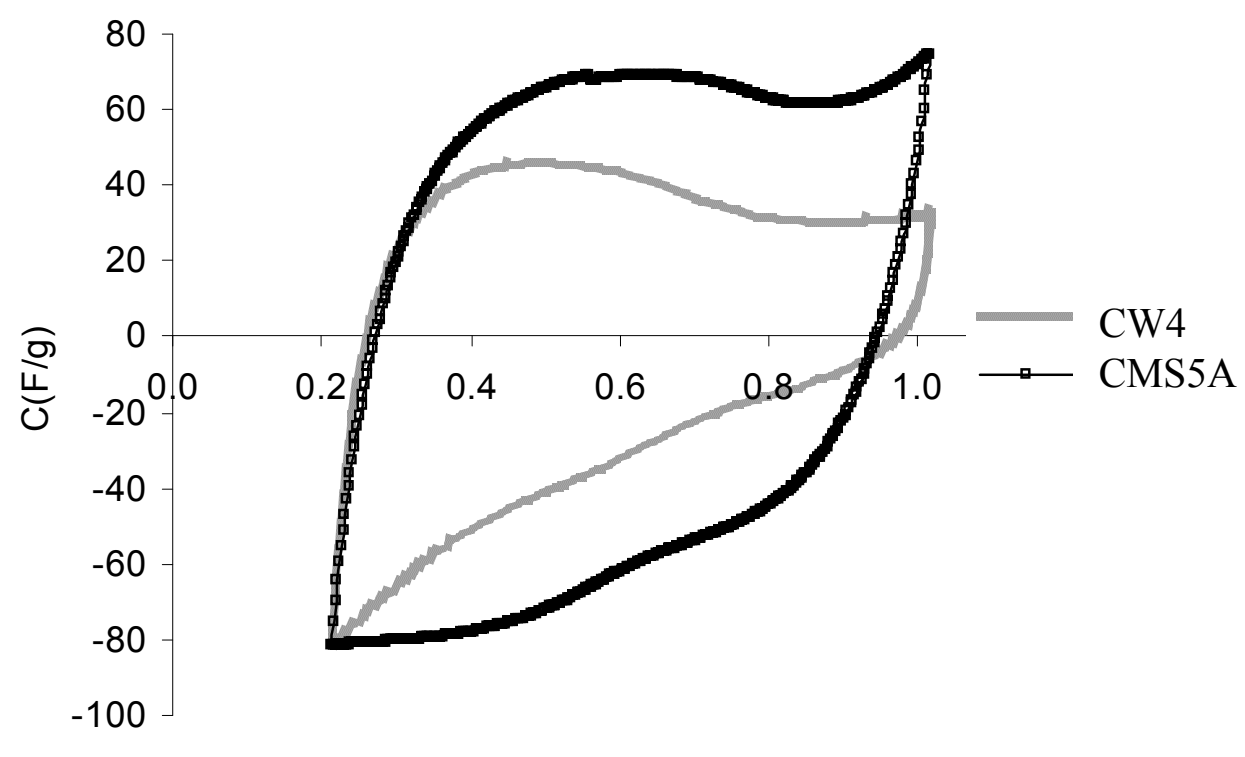

V vs ENH

Figure 4 